6.

\title{
Fixirungsmethode der Golgi'schen Präparate des centralen Nervensystems.
}

(Aus dem Pathologischen Institut zu Berlin.)

Von Dr. Al. Obregia,

Chef des travaux de institut physiologique de Bucarest.

Die von Golgi gefundene Imprägnationsmetbode mit Silber oder Sublimat bat schon die Bestätigung der Anatomen erhalten. Die oft sehr schönen, nach dieser Methode gelieferten Präparate dürfen leider nicht mit einem Deckgläschen versehen werden, wenn man sie aufbewahren will. Die Löslichkeit des chromsauren Silbers in Wasser oder scbwachem Alkohol schliesst ferner jede gute Nachfärbung der Silberpräparate aus. Bekanntlich aber sind gerade die Silberpräparate viel eher (besonders mit dem Osmiumverfahren von Golgi oder Ramon y Cajal) und häuffg schöner darzustellen.

Die von $\mathrm{Pal}$ empfohlene Nachbehandlung mit Natronsulfid $\left(\mathrm{Na}_{2} \mathrm{~S}\right)$ giebt leider zu oft Bräunungen des Feldes und gestattet auch keine Zudeckung mit Gläschen.

Um diese Nachtheile zu vermeiden, bin icb auf das folgende Verfahren gekommen. Die nach Golgi behandelten Stückchen mit Sublimat oder Silber - letztere aus absolutem Alkohol - thut man gut, direct, ohne Einbettung, zu schneiden. Es gelingt vortrefflich. Will man aber durchaus einbetten, so kann das ebenso gut mit Paraffin, wie mit (Celloidin) Photoxylin geschehen. Man muss nur nie schwächeren Alkohol, als solehen von 94-95, anwenden (Silberpräparate). Die Scbnitte brauchen nicht dünn sein.

A. Die aus absolutem Alkohol erbaltenen Schnitte werden in das folgende Bad eingetragen:

Iprocentige Goldehloridlösung in destillirtem Wasser 8-10 Tropfen, absoluter Alkohol. . . . . . . . . . . $10 \mathrm{ccm}$.

Diese Mischung muss $\frac{1}{2}$ Stunde vorher gemacht und dem weissen Licht ausgesetzt werden. Sofort nach dem Einlegen der Scbnitte wird das Bad im Dunklen gelassen oder zugedeckt. Allmählich wird das Silber durch Gold ersetzt - gerade wie im photographischen Papier - oder das Quecksilber in Goldamalgam umgewandelt (Sublimatpräparate). Es erscheinen am Ende auf weissem Felde schwarze, zierliche Zeichnungen. Werden die Schnitte von aktinischem Lichte getroffen, so zeigt sich in derselben Zeit eine Färbung: die Marksubstanz blauviolett, die graue bellrosa und die Körnchenschicht des Kleinhirns dunkelrotb. Für die Fixirung des Golgi'schen Bildes ist es aber besser, das Licht und somit diese Färbung zu vermeiden. Je nach der Dicke der Schnitte sind 15-30 Minuten Dauer des Goldbades hinrejchend, etwas mehr scbadet nicht viel. 
B. Nun werden die Schnitte rasch durch schwachen (50procentigen) Alkohol in destillirtes Wasser abgespült und in folgendes Bad getragen:

Untersehwefligsaures Natron cryst. 10,0 .

Destillirtes Wasser. . . . 100,0.

Hier bleiben die Schnitte, je nach der Dicke, 5-10 Minuten. Werden sie länger darin gelassen, so erscheinen die Zeichnungen blasser; noch weiter, so verschwinden die feinen Fasern. Man schliesst mit tüchtigem Abspülen in destillirtem Wasser, $z$ weimal erneuert.

Nun sind die Schnitte so fixirt, dass man alles mit ihnen anfangen kann. Nachfärbung mit Carmin, Hämatoxylin, Bebandlung nach Weigert oder Pal u.s.w. sind möglich; ebenso Aufhellen in Creosot, Einschliessen in dickes Damarharz. Man kann sie rubig mit Deckgläschen versehen. Diese Versuche waren bereits vorgeschritten, als ich die umfangreiche Arbeit von Sehrwald (Archiv für wissenschaftl. Mikroskopie. Jena 1890) zu lesen bekam. Nach Versuchen von sehr zablreichen Fixirungsmitteln, unter denen auch das Gold, kommt $\mathrm{Sehrwald} \mathrm{zu} \mathrm{dem} \mathrm{Schlusse,} \mathrm{dass} \mathrm{alle} \mathrm{nichts} \mathrm{taugen.}$ Anstatt alkoholisehe, hat dieser Forseber wässerige Goldlösung genommen; dadurch ist sein Misserfolg zu erklären. -

Ich branche kaum zu betonen, dass, während der Gold- und Natronbehandlung die Schnitte nur mit Glas-, nicht mit metallischen Nadeln berübrt werden dürfen. In fertigen Präparaten erseheint die Farbe der Ganglienzellen und anderer Gebilde rom tiefsten Schwarzgrün bis Dunkelviolett, je nach der Dauer der Gold- und Natronbäder. Bei einer kleinen Erfahrung erreicht man diese Töne nach Belieben. 